\author{
Asian Journal of Economic Modelling \\ $\operatorname{ISSN}(e): \quad 2312-3656$ \\ $\operatorname{ISSN}(p): \quad 2313-2884$ \\ DOI: $10.18488 /$ journal.8.2014.22.52.68 \\ Vol. 2, No. 2, 52-68 \\ (C) 2014 AESS Publications. All Rights Reserved. \\ URL: www.aessweb.com
}

\title{
IMPROVING ENERGY CONSERVATION USING SIX SIGMA METHODOLOGY AT FACULTY OF COMPUTER AND MATHEMATICAL SCIENCES (FSKM), UNIVERSITI TEKNOLOGI MARA (UITM), SHAH ALAM
}

\author{
Nur Hidayah binti \\ Mohd Razali ${ }^{++}$ \\ Wan Mohamad Asyraf \\ Bin Wan Afthanorhan ${ }^{2}$
}

\author{
(+ Corresponding author) \\ ${ }^{'}$ Department of Computer and Mathematical Science, Universiti Teknologi Mara \\ Shah Alam, Malaysia \\ ${ }^{2}$ Department of Mathematics, Faculty of Science and Technology, Universiti \\ Malaysia Terengganu, Malaysia
}

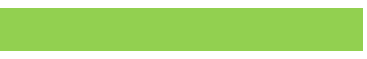

\section{Keywords}

Six sigma methodology

Electrical consumption

Pareto chart

DMAIC process

UiTM Shah Alam

Business performance

Energy conservation.
Electrical consumption is increasing rapidly in Malaysia due to the sustenance of a modern economy way of living. Recently, the Vice Chancellor of University Technology MARA, Tan Sri Dato' Professor Ir Dr Sahol Hamid Abu Bakar has shown a great deal of concern regarding the high electrical energy consumption in UiTM's main campus in Shah Alam. This study seeks to evaluate the factors that contribute to high electrical energy consumption in the Faculty of Computer and Mathematical Sciences (FSKM), UiTM using the Six Sigma methodology and to compare electrical energy consumptions before and after the EC (Energy Conservation) initiative campaign. Many companies worldwide continue to achieve improvements in business performance using the Six Sigma approach. The electrical consumption from January 2011 until December 2013 was analyzed using five stages of Six Sigma which is Define, Measure, Analyze, Improve and Control (DMAIC). The total electrical consumption for 2011 was 1, 648, $791 \mathrm{kwH}$ (RM 514,422.79) and 1, 657, $808 \mathrm{kwH}(\mathrm{RM}$ $517,236.10)$ in 2012 which is an increase of $0.5 \%$ (RM 2813.31 or 9017 kwH). From the results obtained, Pareto chart shows that airconditioner $(57 \%)$ is the major factor that contributes to high consumption of electricity, followed by lightings (22\%), sockets $(16 \%)$ and others $(5 \%)$. The electrical consumption was almost doubled when the new semester begun. After the campaign, there was a reduction of $2 \%$ in electrical consumption. This study has successfully implemented Six Sigma methodology which involves a systematic DMAIC process to evaluate electrical consumption in FSKM. 
Contribution/ Originality: The paper contributes the first logical analysis using six-sigma methodology to equip the necessary of objective research that has been provided once identify the limitation of electricity consumption in the selected population. Of using this application, the readers will discern the main factor thru comparing of implementation of program suggested in order to what extent the efficiency of concepts used.

\section{INTRODUCTION}

Over the decades, there has been a great increase in demand for electrical energy in our daily lives. Most of our daily activities would involve the use of electrical devices which require an adequate amount of electrical energy depending on the types of devices being used and the frequency of use. For example, refrigerators, fans, computers and Internet usage in this new globalization era require electricity. According to Brandon and Lewis (1999) domestic energy consumption represents an area where the links between global environmental problems and individual behaviorism are clearly identifiable, even if consumers do not immediately recognize the connection. They highlighted how the increase in the participants' awareness related to their behavior and how it was connected to problems such as global warming. On college campuses, the vast majority of energy consumption takes place within the buildings (Petersen et al., 2007). A comprehensive study of greenhouse gas emissions conducted by the Rocky Mountain Institute found that $92 \%$ of the 46500 tonnes of carbon dioxide equivalents released by Oberlin College in 2000 could be attributed to heating, cooling, lighting and other energetic services provided to buildings (Heede and Swisher, 2002). Individuals who have a higher degree of connectedness with nature are more likely to make decisions beneficial to the environment (Mayer and Frantz, 2004) while students who are supplied with information on environmental consequences of resource use can decrease electricity usage (Petersen et al., 2007). On the use of electrical consumption as a research subject, the main objective research is to compare electrical consumption before and after the campaign executed. Thus, the six-sigma methodology is fitting to achieve the required objective paper and eventually the findings suggested will be implementing to reduce the usage of electricity among students and staffs.

\section{METHODOLOGY}

Many companies worldwide continue to achieve improvements in business performance using the Six Sigma approach. Statistically, Six Sigma refers to a process in which the range between the mean of a process quality measurement and the nearest specification limit is at least six times the standard deviation of a process (Fursule et al., 2012). It is a disciplined, data driven approach and methodology for eliminating defects in any process. A Six Sigma defect is described as anything that is outside customer specifications, an imperfection and a non-conformance. Overall, the main objective of Six Sigma is to center the process on the target and reduce the process variation. In fact, Six Sigma is also known as a problem solver that reduces cost and improves customer satisfaction. As a Metric, when a process is operating at Six Sigma level, it will produce non-conformance (i.e., defects or errors) at a rate of not more than 3.4 defects per one million opportunities (Ansari et al., 2009). Six-sigma involves a systematic procedure which comprises of 
five stages known as DMAIC. In other words, DMAIC phases stands for Define, Measure, Analyze, Improve and Control. The objectives, statistical techniques and the variables involved are given in Table 1.1.

Table-1.1. Objectives and Data Analysis Techniques

\begin{tabular}{c|l}
\hline Stage & \multicolumn{1}{c}{ Objective } \\
\hline \multirow{2}{*}{ Define } & - To identify the electrical consumption’s problem in Faculty of Computer and \\
& Mathematical Sciences (FSKM) \\
\hline Measure & -To evaluate the electrical component that has the highest electrical consumption \\
\hline Analyze & - To compare the electrical consumption before and after semester begin (time) \\
\hline Improve & - To compare electrical consumption before and after the campaign. \\
\hline Control & - To monitor electrical consumption in FSKM. \\
\hline
\end{tabular}

\section{ANALYSIS}

The results obtained from the study had been reported based on the five-step improvement cycle of DMAIC (Define, Measure, Analyze, Improve and Control).

\subsection{Define Stage}

The research scope covers Zone D in UiTM Shah Alam and FSKM is chosen due to the fact that it was listed as one of the top three faculties with high electrical consumption. Thus, the main objective of this project is to reduce the electrical consumption in FSKM by creating awareness among staffs and students. Based on process mapping of Figure 1.1, TNB is the supplier and provides electricity from generating stations to UiTM as the sub-transmission customer. The electricity usage involves office, classroom, computer laboratory and tutorial hall in FSKM.

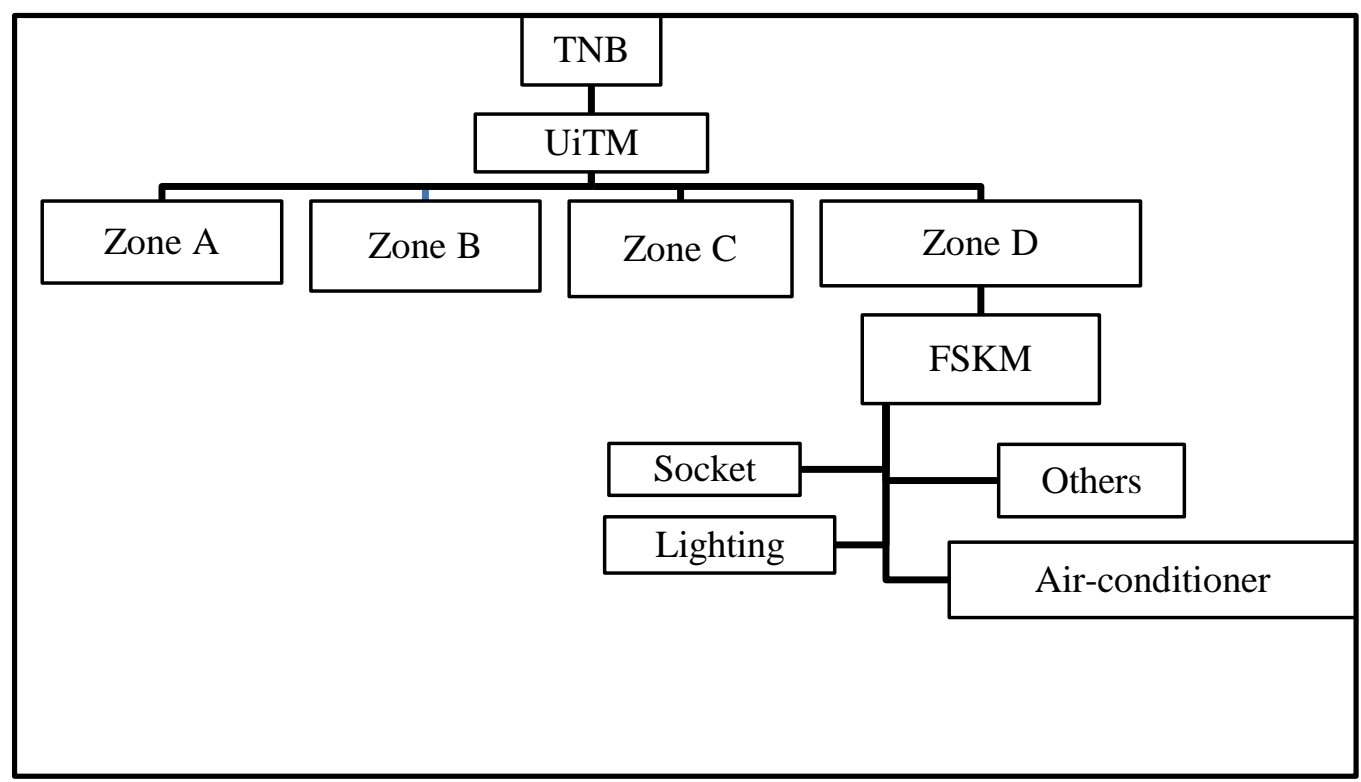

Figure-1.1. Process Mapping 


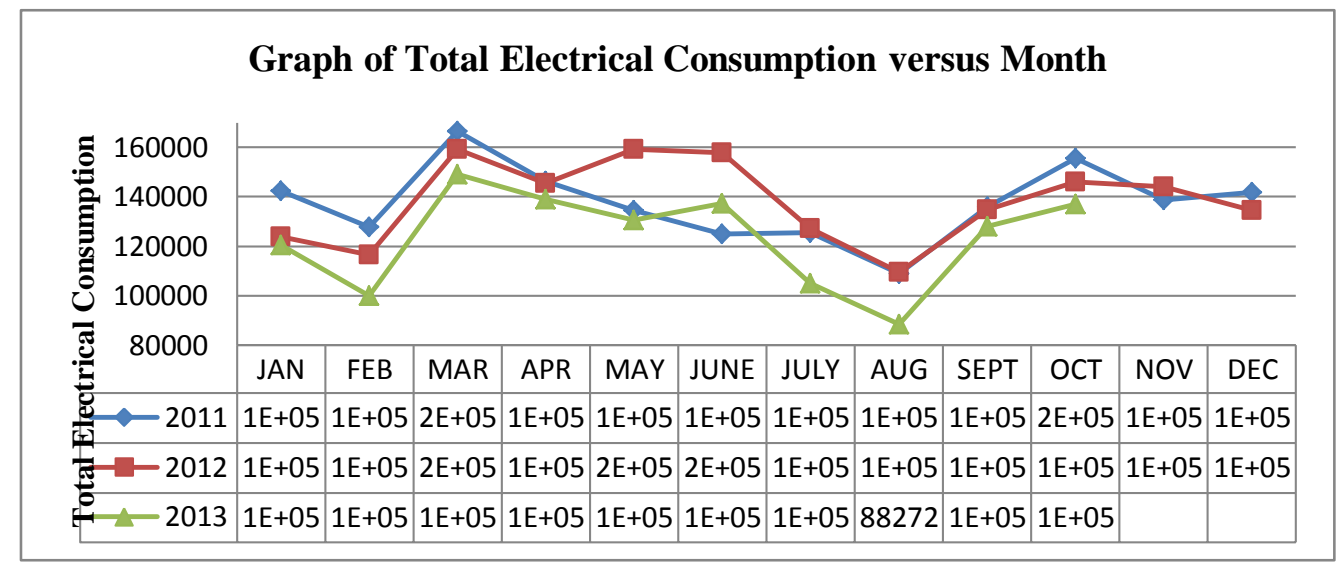

Figure-1.2. Total electrical consumption (January 2011 until October 2013)

From the figure, in March and September, there was high usage since semester began while there was low usage especially in July to August and January to February because of semester break. The electrical consumption from April 2012 until July 2012, show a decreasing trend due to the 4-month semester break by government's policy. This is expected as fewer classes during semester break are being conducted and less curriculum activities were carried out.

Total electrical consumption for 2011 was 1, 648, $791 \mathrm{kwH}$ (RM 514,422.79) and increased to 1, 657, $808 \mathrm{kwH}(\mathrm{RM} 517,236.10)$ by $0.5 \%$ (RM 2813.31 or $9017 \mathrm{kwH})$ in 2012.

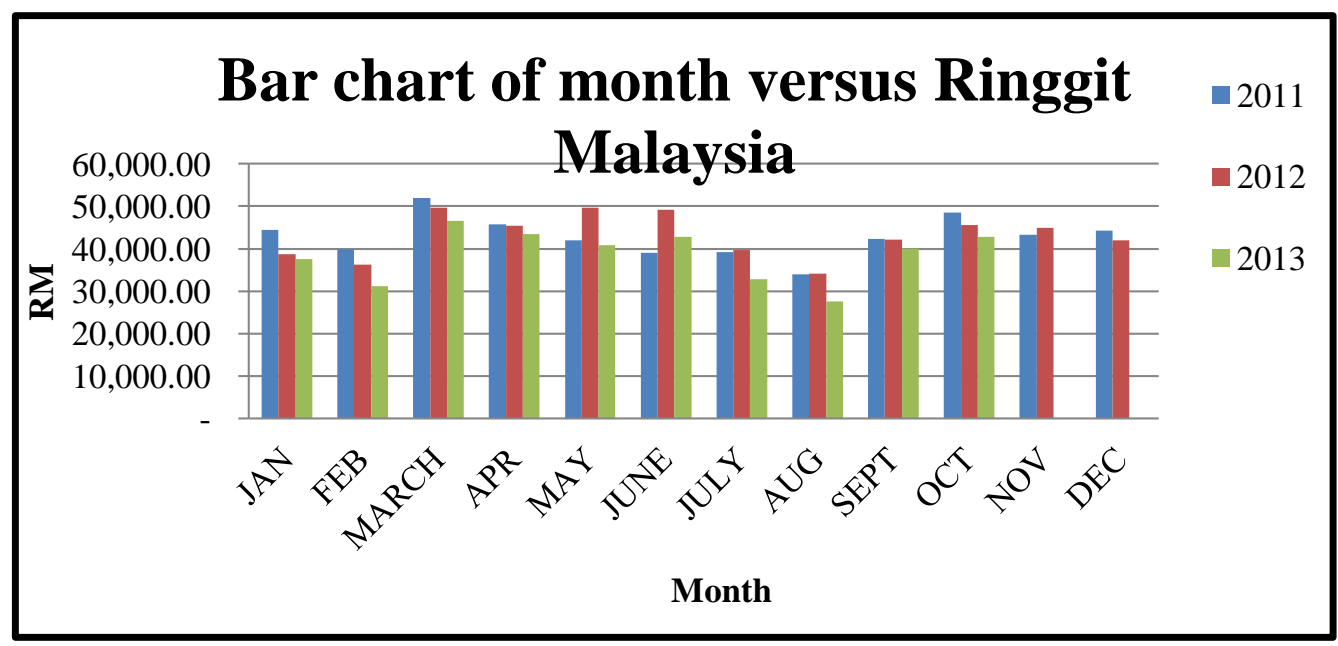

Figure-1.3. Bar chart of electrical costs (Ringgit Malaysia) for each month 
Based on Figure-1.3, the electrical consumption seems to decrease from 2011 to 2013 for each month but FSKM is still among the top three with highest usage of electricity in Zone D.
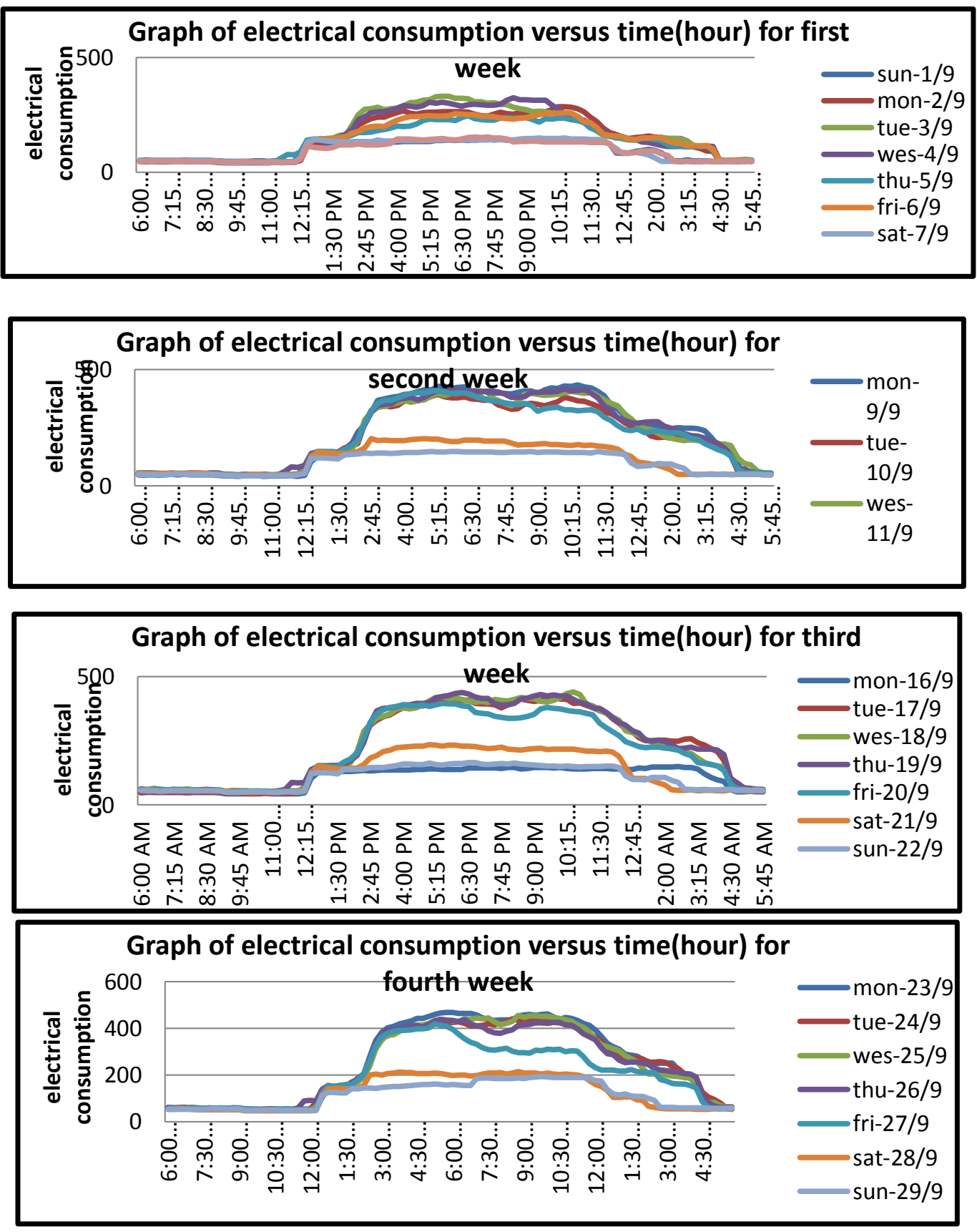

Figure-1.4. Hourly data of electrical consumption for each week of September 2013

The first week showed that the electrical consumption was lower than other weeks since the semester has not started yet as the new semester began on 9th of September. From the graphs, we can conclude that the electrical consumption start decreasing at $10.30 \mathrm{am}$ and the peak usage is between $4.00 \mathrm{pm}$ to $10.15 \mathrm{pm}$. However, there is still high usage of electricity from $12.00 \mathrm{am}$ 
until $4.30 \mathrm{am}$. This could be electrical consumption by computer servers, lights or air-conditioner. Further explanation will be discussed at the Control stage.

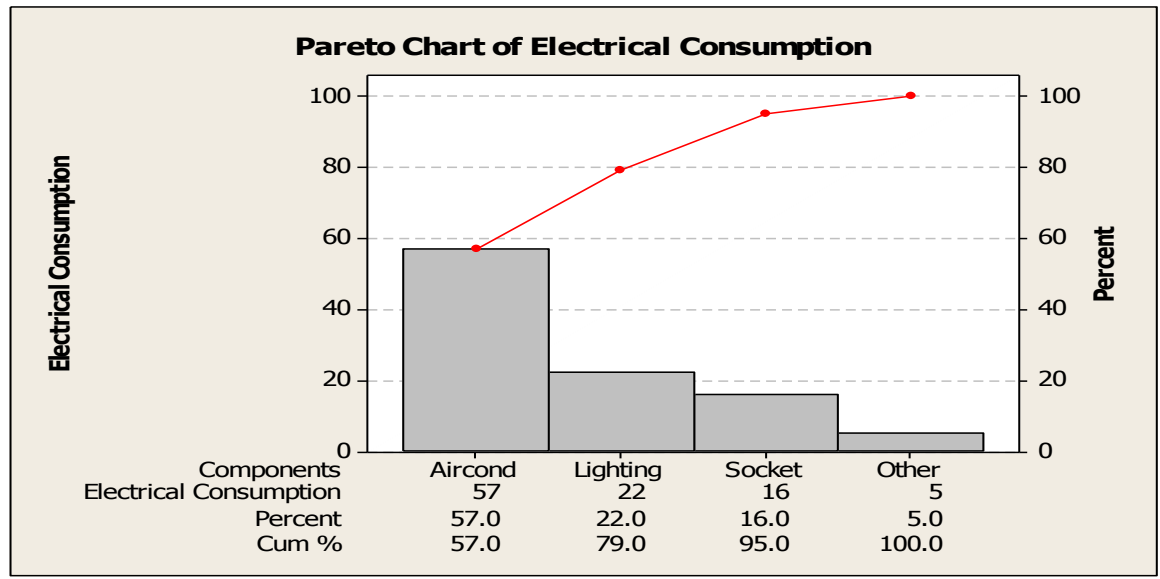

Figure-1.5. Pareto chart of electrical consumption (December 2013)

Based on Figure 1.5, the component that has highest electrical consumption is air-conditioner $(57 \%)$, followed by lighting (22\%), socket by $(16 \%)$ and lastly others which $(5 \%)$.

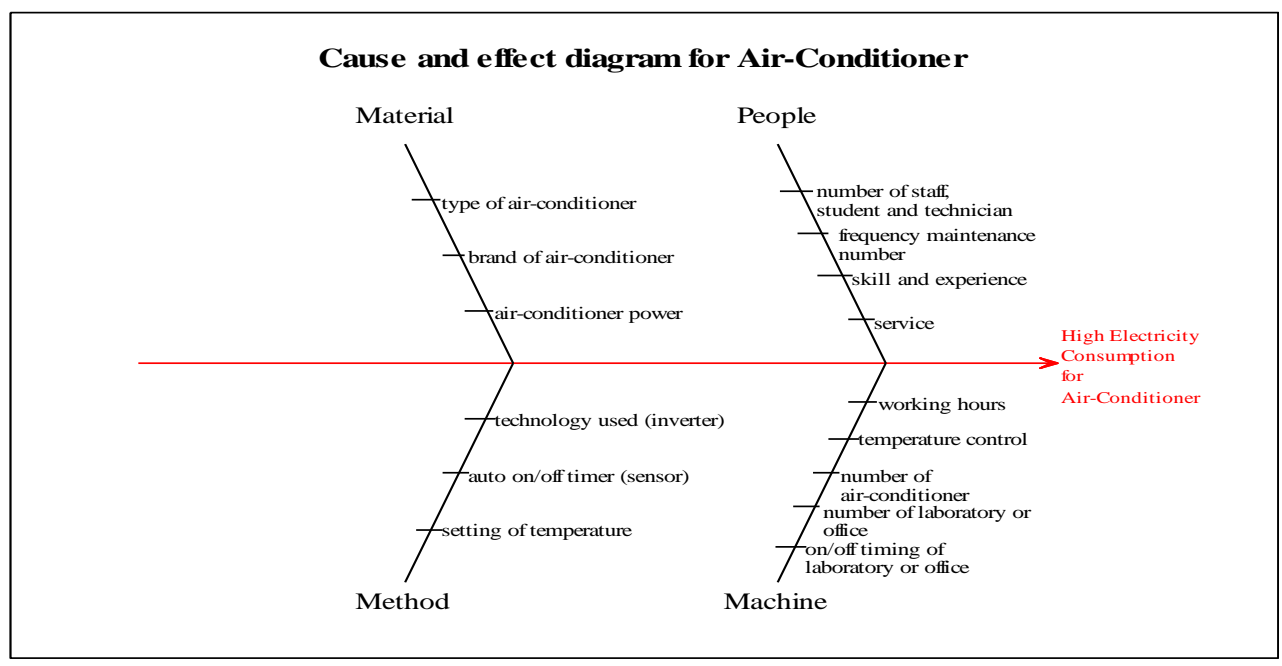

Figure-1.6. Cause and effect diagram for air-conditioner

Based on Figure 1.6, the problem areas identified were classified as 'Material', 'People', 'Method' and 'Machine'. The problem area under 'Material' is type, brand and power of the airconditioner. Sometimes, a high-quality brand will use expensive equipment such green technology that can save power energy. Under 'People', the problems identified are number of staff, students, technician, frequency maintenance, skills, experience and service. It is a must for the air-conditioner to be serviced in order to maintain its performance such as getting the fan of the air-conditioner checked and cleaned. Next, the high consumption of electricity also depends 
on 'Method' which is comprised of the technology used (inverter), timing of auto on or off sensor and the setting of the temperature. Lastly, for 'Machine', it involves on or off timing of laboratory, office or air-conditioners, number of laboratory, temperature control and working hours of the staff.

\subsection{Analyze Stage}

Firstly, the I-MR chart was constructed for the daily electrical consumption from $1^{\text {st }}$ of August 2013 until $31^{\text {th }}$ of October 2013 excluding weekends.

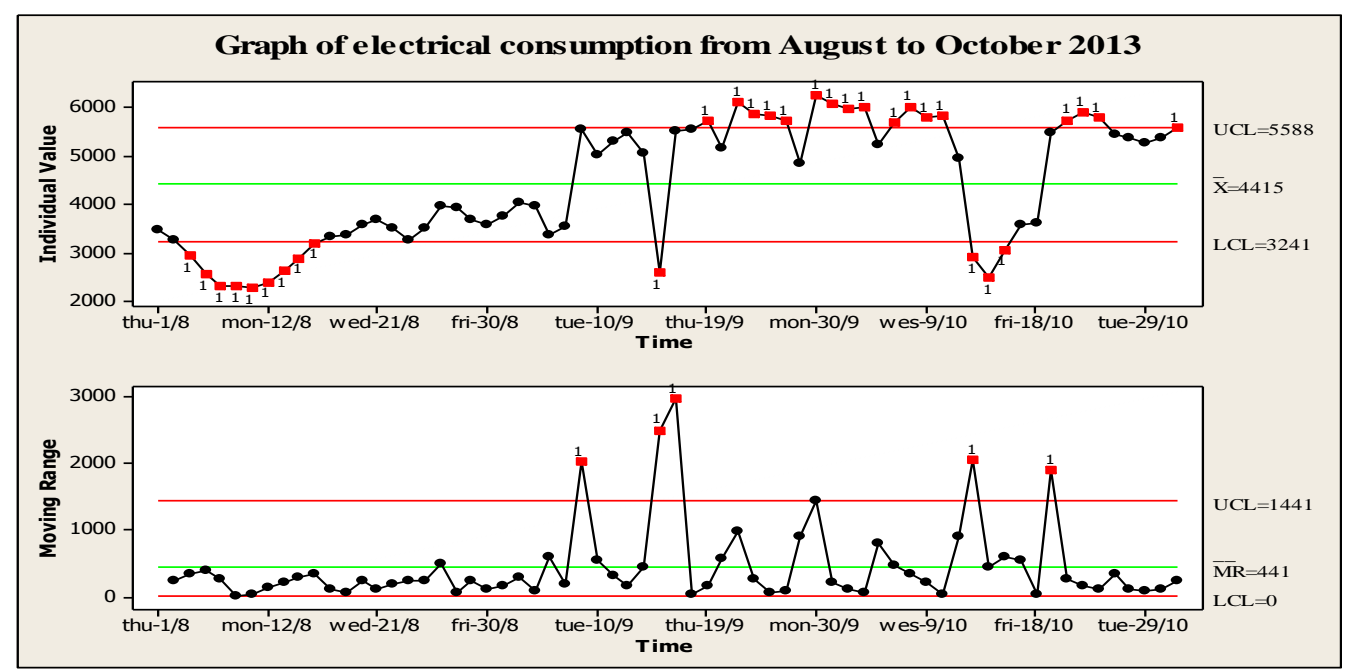

Figure-1.7. I-MR Chart of daily electrical consumption from August to October 2013

The I-MR value chart in Figure 1.7 shows that the electrical consumption was low in the month of August due to semester breaks. The low consumption at point 5 ( $8^{\text {th }}$ Aug) until $11{\text { ( } 13^{\text {th }}}^{\text {th }}$ Aug) was due to Hari Raya Puasa whereas at point $33,16^{\text {th }}$ of September was a public holiday for (Hari Malaysia). At point 28 ( $9^{\text {th }}$ September), the electrical consumption started to increase since it was the start of a new semester for (September 2013 until January 2014). Next, on point 53 (14 $4^{\text {th }}$ October) and 54 ( $15^{\text {th }}$ October), the electrical consumption is low because it is Hari Raya Aidiladha. Next, we analyzed the relevant data by removing all the public holidays, and the results of I-MR graph is shown in Figure 1.8 below. 


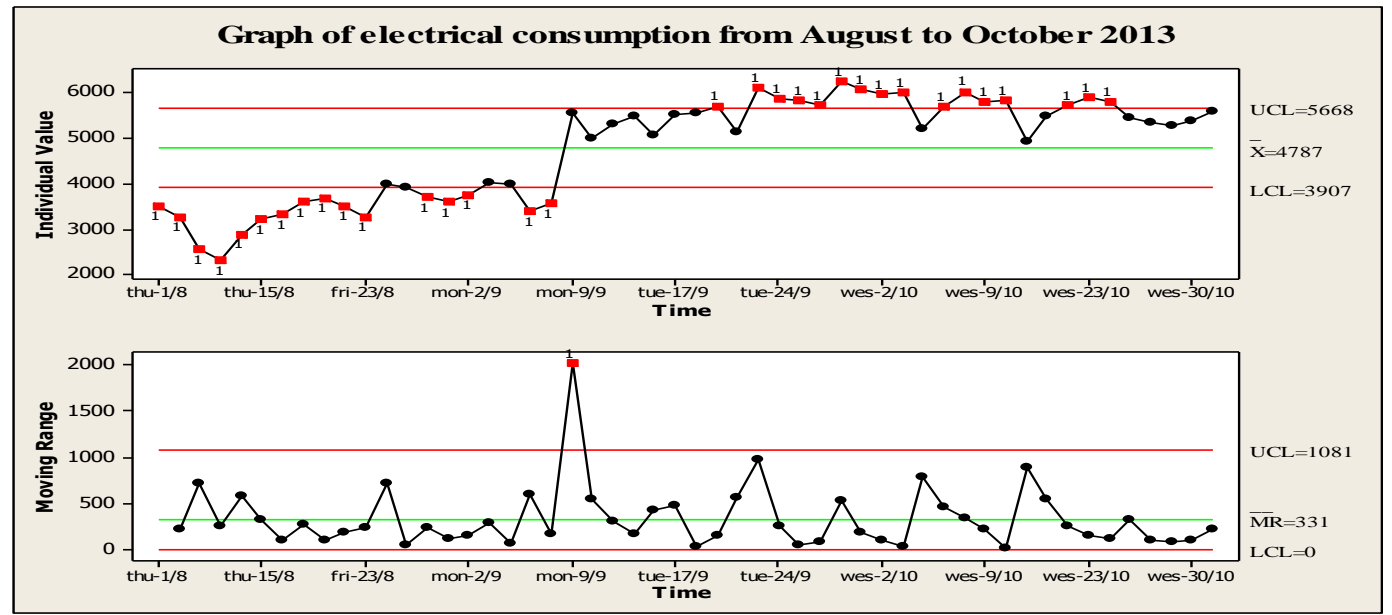

Figure-1.8. I-MR Chart of electrical consumption from Aug to October 2013 (After removing public holidays)

Based on the Moving Range chart in Figure 1.8, there was a high peak at point 21 (out of control point). This is due to the beginning of semester as students start their class and conduct their activities. The individual chart shows on $9^{\text {th }}$ of September, the electrical consumption seemed to increase high and it could be seen there are two different patterns (low and high electrical consumption). The first group on the left side is during the semester break with majority of the points below the lower control limit and on the right side where all points are above the center limit is when the semester is on.

Therefore, to compare the electrical consumption during semester breaks and when the class started (semester begins), after removing weekends and public holidays, the 20 data for each group was used as follows:

- Semester break is between $1^{\text {st }}$ of August until $8^{\text {th }}$ of September 2013

- Semester begin is between $9^{\text {th }}$ of September until $8^{\text {th }}$ of October 2013

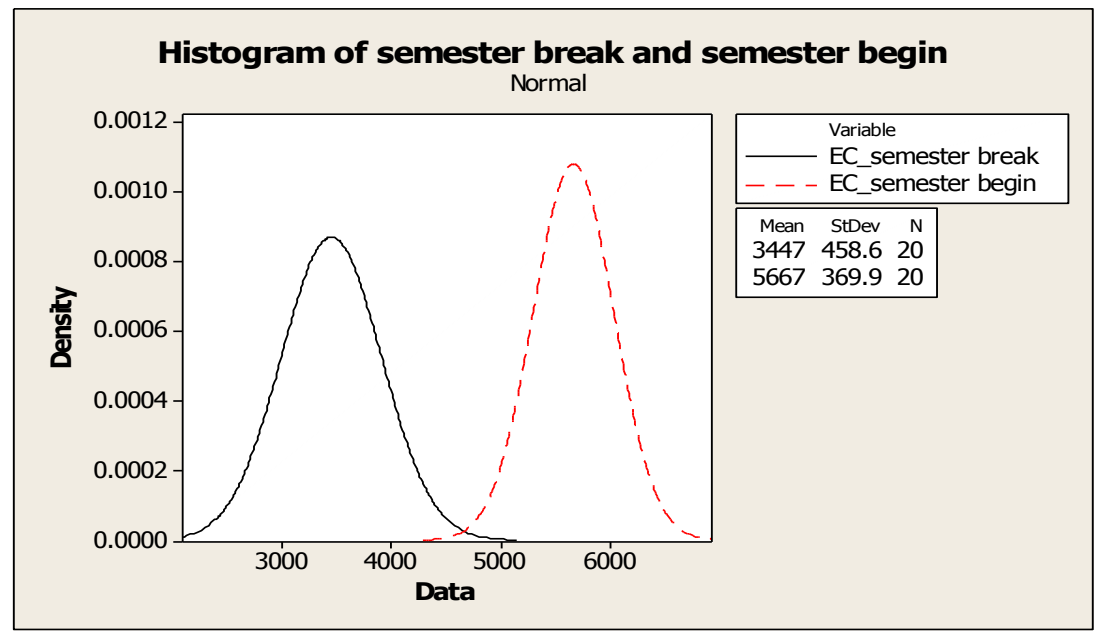

Figure-1.9. Histogram for semester break and semester begin 
Figure 1.9 shows the average electricity consumption was at $3.447 \mathrm{kwH}$ during the semester break and increased to an average of $5.667 \mathrm{kwH}$ when the semester began (start).

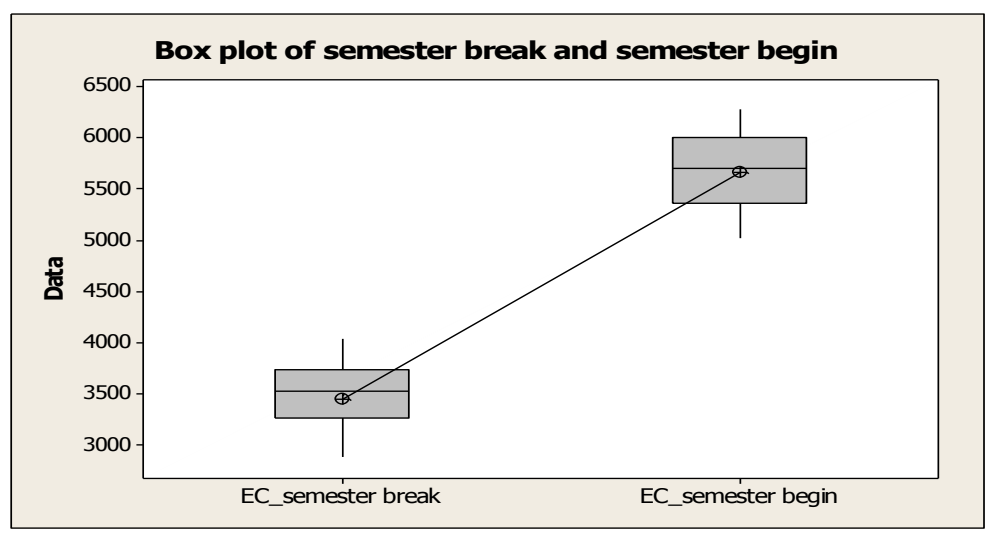

Figure-1.10. Box plot of electricity consumption

Based on Figure 1.10, we can identify that the electrical consumption is almost double when semester start. Thus, the objective of this project is to reduce the electrical consumption by $2 \%$ by the end of 2013 with the purpose to trigger awareness on energy conservation initiatives campaign.

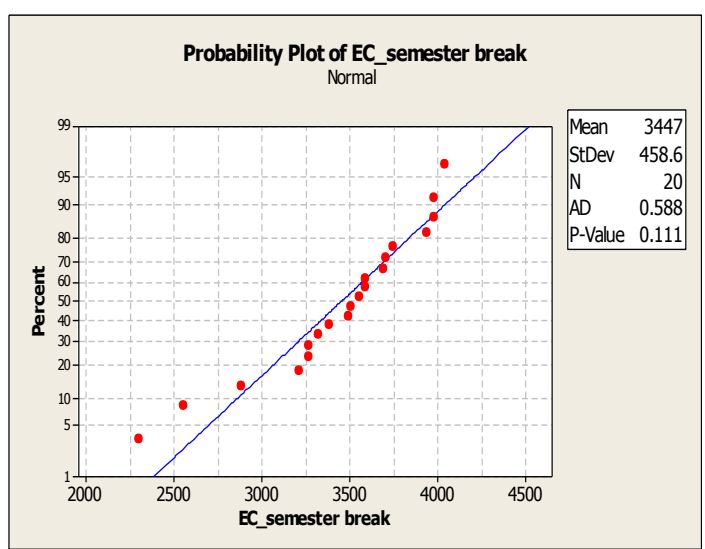

Figure-1.11. Normal probability plot of electrical consumption during semester break

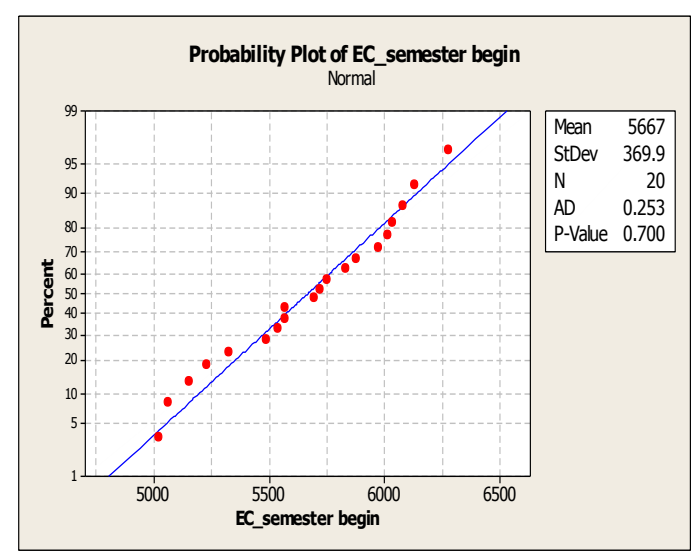

Figure-1.12. Normal probability plot of electrical consumption during semester begin

From Figure 1.11 and Figure 1.12, the probability plot shows most of the points were lying on the straight line. In the accordance of Chambers et al. (1983), the normal probability plot is a graphical technique for assessing whether or not a data set is approximately normally distributed. The proposed method suggests once the plot is lying at the straight line presented, one can conclude that the data is achieved to be normal and accepted for the subsequent analysis concerning on parametric assumption. In doing so, the author prone to probing this research based on the objective research that has been stressing on the previous subtopic (Introduction). This proved that we have enough evidence to conclude that the distribution is normally 
distributed. Moreover, both $p$-values are greater than $\alpha=0.05$, thus proves the data is normally distributed. In particular, this probability value is derived by Monte Carlo procedures to evaluate the power of normality test using the family wise error-rate to determine whether accept or reject null hypothesis. The null and alternative hypotheses are presented as:

$\mathrm{H}_{0}$ : The distribution is normal $(\mathrm{p}>0.05)$

$\mathrm{H}_{1}$ : The distribution is not normal $(\mathrm{p}<0.05)$

Based from Figure 1.13, we can indicate that the graph is skewed to the left on electrical consumption during semester break while a bell shaped curved is defined for the electrical consumption when semester begins in Figure 1.14. However, based from the Skewness value, it concludes that both graphs were normally distributed since the values were in the range. The mean for semester break is $3446.8 \mathrm{kwH}$ less than mean when semester has begun $5666.6 \mathrm{kwH}$. The Anderson-Darling normality test is not significant since both are 0.111 and 0.700 (p>0.05), thus indicates that the distribution is normal. According to Farrell and Rogers-Stewart (2006), Anderson Darling test is a modification of the Cramer-Von Mises (CVM) test. It differs from the CVM test in such a way that it gives more weight to the tails of the distribution. Arshad et al. (2003) concur to declare this test is the most powerful for formal normality test. Since the sample data is small $(\mathrm{n}<30)$, the Mann-Whitney test (a non-parametric test) was also performed and the results are similar to the Two-Independent Samples T-test as shown in Figure 1.15

Figure-1.13. Summary for electrical Consumption during semester break

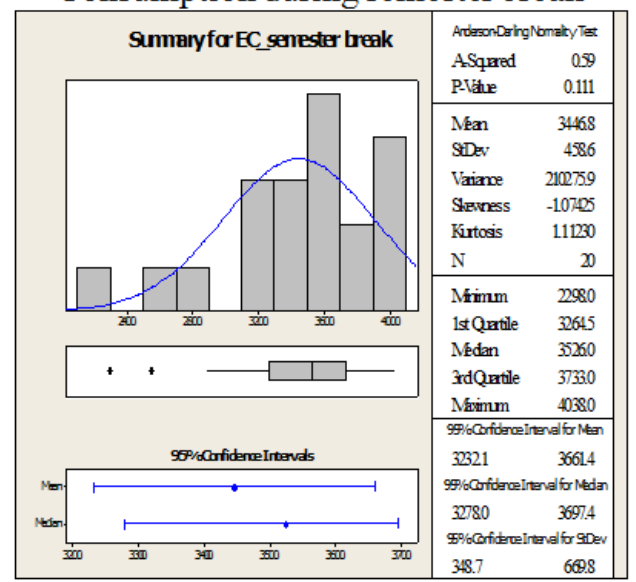

Figure-1.14. Summary for electrical consumption when semester begin

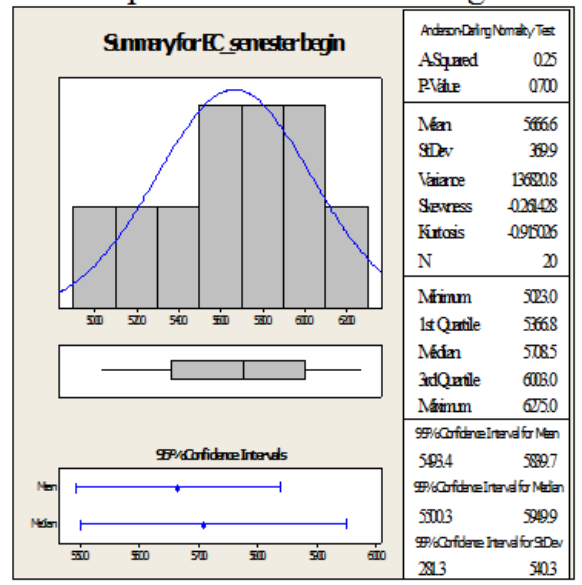

Hence, we have enough evidence to conclude that electrical consumption for semester begins is significantly higher than electrical consumption during semester break. 


\section{Two-Independent Samples T-test}

$\begin{array}{lllcc} & \text { N } & \text { Mean } & \text { StDev } & \text { SE Mean } \\ \text { EC_semesterbreak } & 20 & 3447 & 459 & 103 \\ \text { EC_semesterbegin } & 20 & 5667 & 370 & 83\end{array}$

95\% CI for difference: $(-2487 ;-1953)$

$\mathrm{T}-$ Value $=-16.85 \mathrm{P}-$ Value $=0.000 \mathrm{DF}=36$

\section{Mann-Whitney Test}

$\begin{array}{lrl} & \text { N } & \text { Median } \\ \text { EC_semesterbreak } & 20 & 3526.0 \\ \text { EC_semesterbegin } & 20 & 5708.5\end{array}$

Point estimate for ETA1-ETA2 is -2184.5

95.0 Percent CI for ETA1-ETA2 is $(-2450.9 ;-1944.0)$

$\mathrm{W}=210.0$

Test of ETA $1=$ ETA 2 vs ETA 1 not $=$ ETA 2 is significant at 0.0000

Figure-1.15. Summary for electrical consumption of Two Independent Samples T-test and Mann-Whitney Test

\subsection{Improve Stage}

In the Improve stage; a campaign entitled Energy Conservation Initiatives Campaign was organized to create awareness among staff and students at Faculty of Computer and Mathematical Sciences. A project was formulated and the head of the project is Associate Professor Dr Nordin Abu Bakar, Deputy Dean of Student Affairs. During the campaign, a talk entitled 'Effects of High Electrical Usage and Ways to Save Electricity' was given by Mr. Razali bin Haji Abdul Hadi, Head of "Unit Kecekapan Tenaga" in UiTM Shah Alam. The two hours talk involved staff and students from FSKM and brochures also had been given to them. In addition to that, stickers were also given to every academic staff, as a reminder for them to switch off all the electrical appliances when not in use. To investigate the campaign has an effect in reducing electrical consumption; only 10 daily data were collected excluding weekend and public holiday. The duration of before and after campaign is as follows:

- Before campaign is between $19^{\text {th }}$ of November until $30^{\text {th }}$ of November 2013

- After campaign is between $1^{\text {st }}$ of December until $12^{\text {th }}$ of December 2013

The effect of certain intervention and treatment is often measured within a short period of time such as measures the effectiveness of taking medicine or vitamins and elections day. 


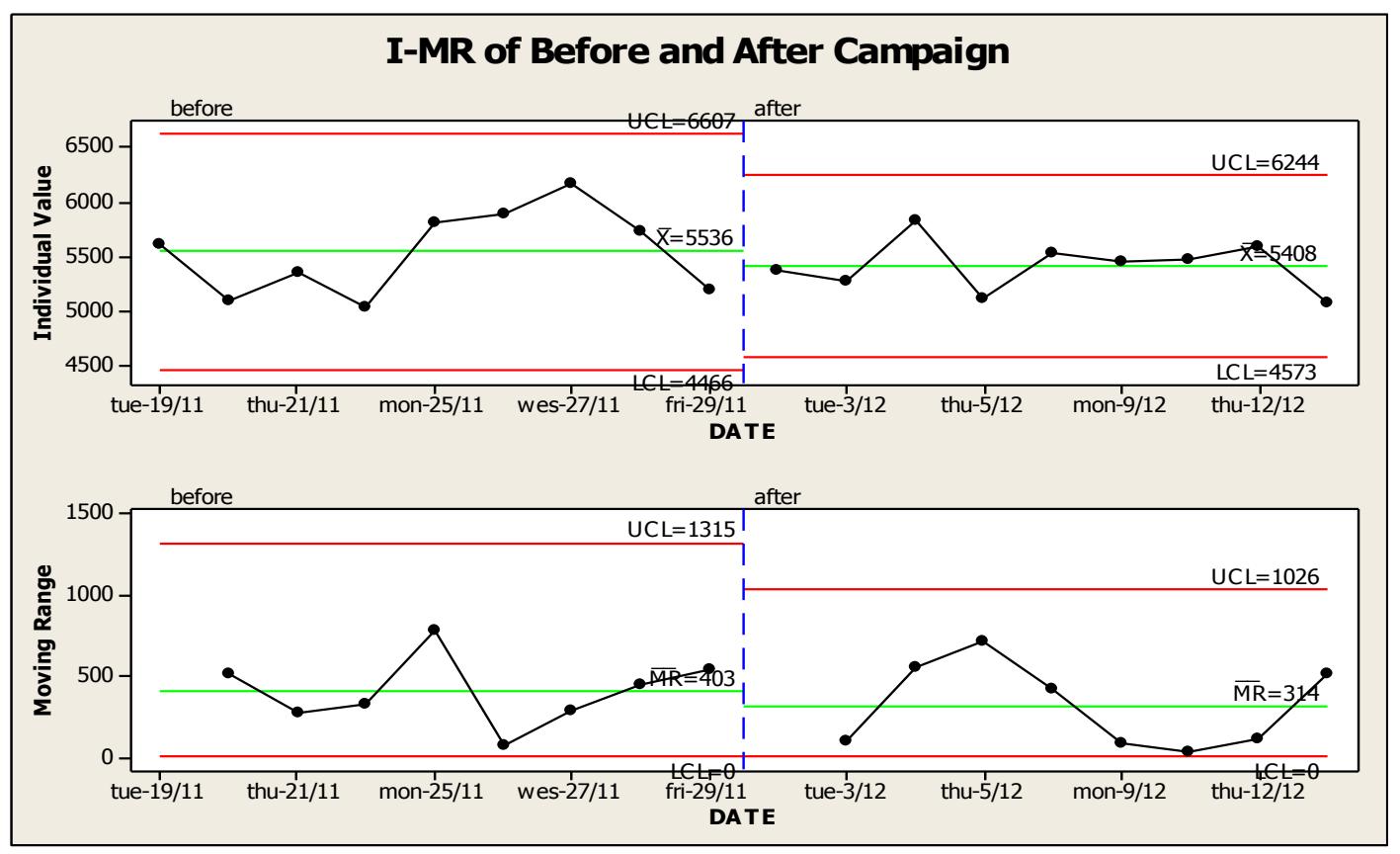

Figure-1.16. I-MR for before and after campaign

Based on the I-MR chart in Figure 1.16, we can conclude that the control limit of electrical consumption decreased after the campaign. This means the variation has decreased in which the upper control limit before campaign is 6607 and decreased to 6244 whereas the lower control limit before campaign is 4466 and it decreased to 4573 . The center line had also decreased from 5536 to 5408 after the campaign. This indicates that the electrical consumption has overall decreased.

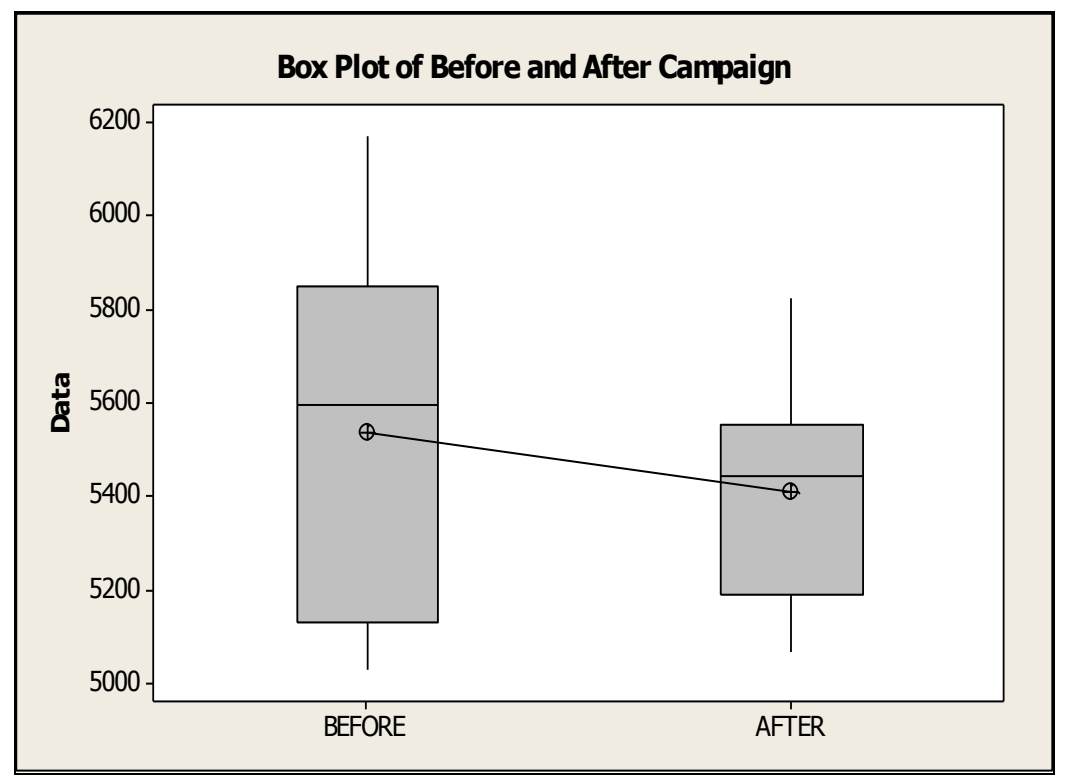

Figure-1.17. Box plot of before and After Campaign 
The box plot in Figure 1.17 shows that the median electrical consumption after campaign is lower than before campaign

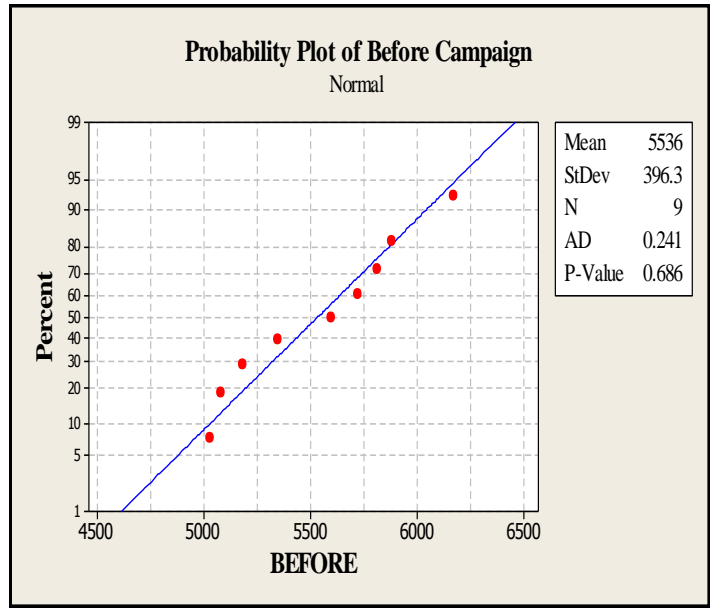

Figure-1.18. Normal probability plot of electrical consumption for before campaign

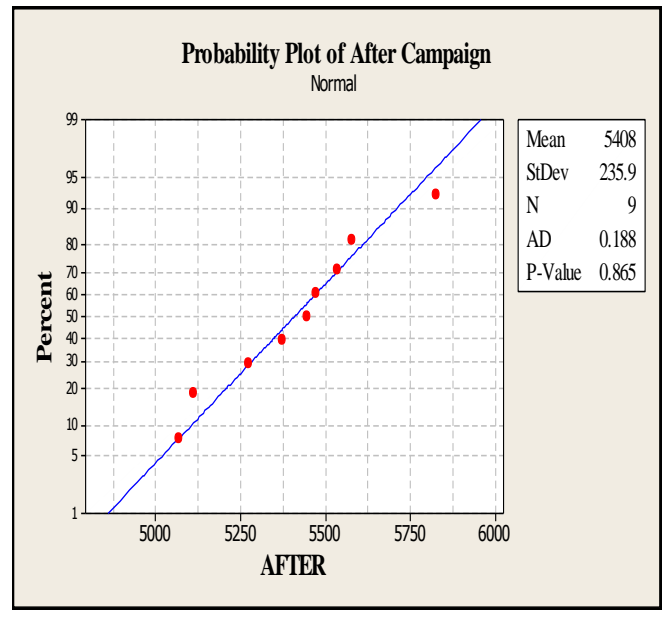

Figure-1.19. Normal probability plot of electrical consumption for after campaign

From Figure 1.18 and Figure 1.19, the probability plot shows most of the point's lies on the straight line. We have enough evidence to conclude that the distribution is normally distributed. Moreover, both $p$-values are greater than $\alpha=0.05$, thus proves the data is normally distributed.

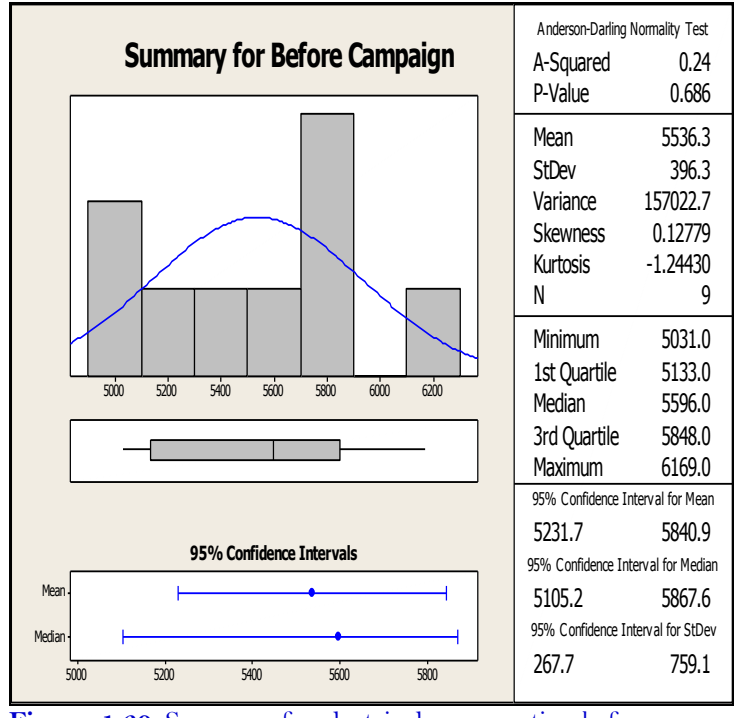

Figure-1.20. Summary for electrical consumption before campaign

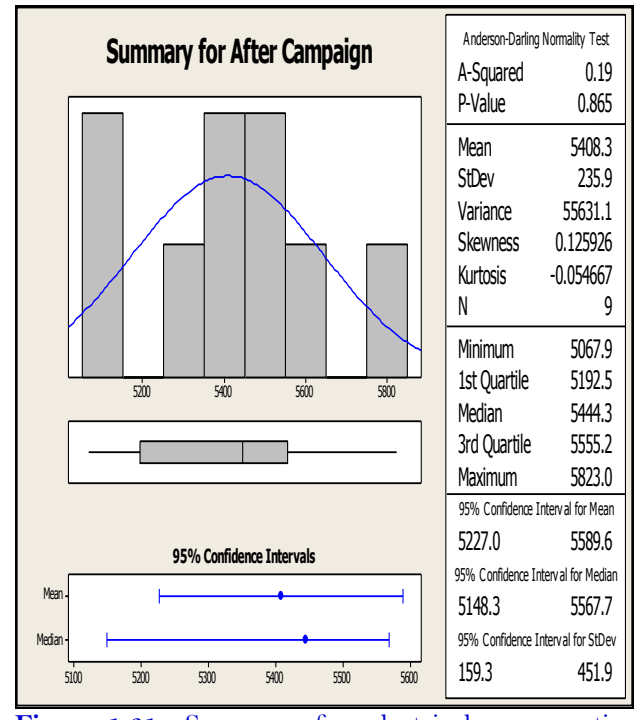

Figure-1.21. Summary for electrical consumption after campaign

Based on Figure 1.20 and Figure 1.21, we can conclude that the distribution of electrical consumption is normally distributed since both skewness values are between the ranges. The Anderson-Darling normality test is not significant ( $\mathrm{p}>0.05)$, and confirms the distribution of electrical consumption is normally distributed. 
Since the sample data is small $(\mathrm{n}<30)$, the Mann-Whitney test (a non-parametric test) was also performed and the results are similar to the Two-Independent Samples t-test.

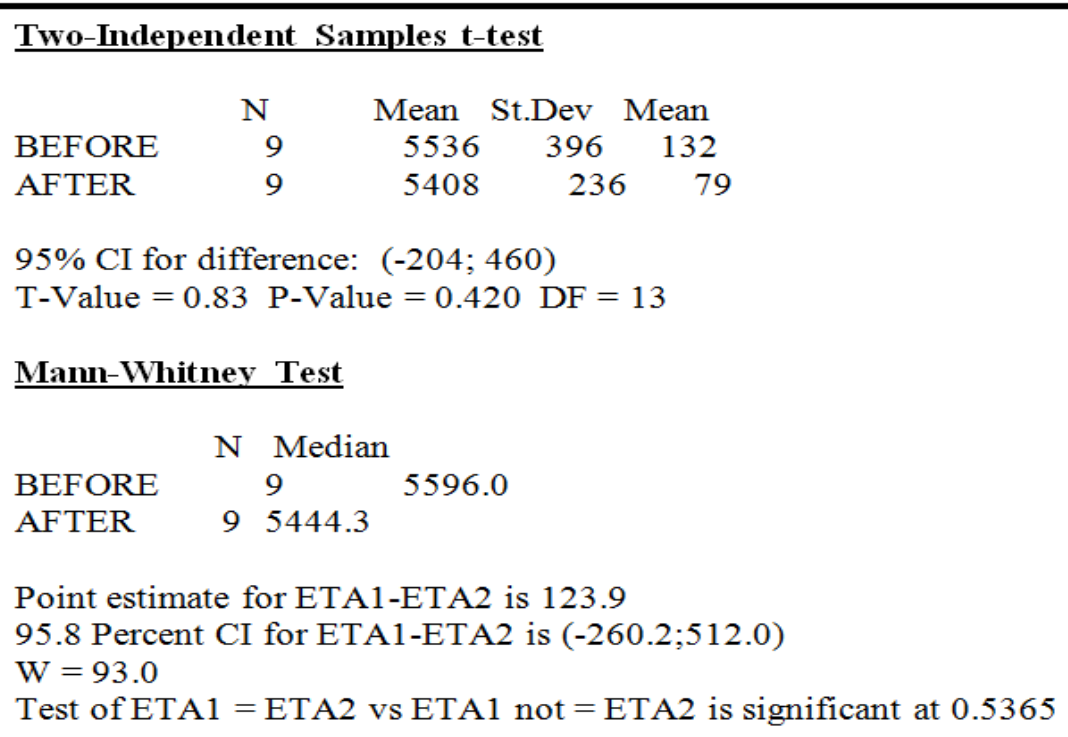

Figure-1.22. Summary for electrical consumption of Two Independent Samples T-test and Mann-Whitney Test

Both p-values of Mann-Whitney result and Two Independent Samples T-test are not significant $(\mathrm{p}>0.05)$. It can be concluded that there is no difference in the electrical consumption before and after campaign. However, there is a reduction to $2 \%$ in electrical consumption after the campaign. More analysis will be carried out using at least 3 months data in the future as this is a one year Energy Conservation (EC) project in FSKM.

$$
\begin{gathered}
\text { Percentage reduction }=\frac{\text { Mean EC_before }- \text { Mean EC_after }}{\text { Mean EC_after }} \times 100 \\
\text { Percentagereduction }=\frac{5536-5408}{5536} \times 100=2.31 \sim 2 \%
\end{gathered}
$$

Although the improvement only contributes to a reduction of $2 \%$, it still can be concluded that the awareness campaign is successful and consumers are taking initiatives to reduce electrical usage by switching off electrical appliances when not in use. In specifically, the consumer start apprehends to acknowledge the usage of electricity once execution the awareness campaign among the staffs and students UiTM Shah Alam. In other words, this campaign is success to undertake the vision to raise public awareness pertaining to electricity use. In doing so, the reduction of electricity consumption might become lesser if the period for execution is extending besides encourages more promotions among consumers.

\subsection{Control Stage}


In the Analyze stage, this study found that there is wastage of electrical energy from 12.00 am until $6.00 \mathrm{am}$. Thus, it is recommended that FSKM introduce an automatic system to shut down the unused electrical usage after 12 midnight. Table 1.2 shows some calculation components of electrical consumption for 24 data per day in September 2013.

Table-1.2. Electrical Consumption for September 2013 from 12.00 am to $6.00 \mathrm{am}$

\begin{tabular}{|c|c|c|}
\hline Electrical Consumption & kwH & $\mathbf{R M}$ \\
\hline $\begin{array}{l}\text { Total actual electrical consumption } 15 \mathrm{kwH} \\
\text { for every } 15 \mathrm{~min} \text { (Actual EC) }\end{array}$ & 25903 & 8081.74 \\
\hline $\begin{array}{l}\text { Assumed value of electrical consumption, } \\
15 \mathrm{kwH} \text { for every } 15 \mathrm{~min} \text { (Assumed EC) }\end{array}$ & $\begin{array}{l}24 \times 15 \mathrm{kwH} \times 30 \text { days }= \\
10800\end{array}$ & $\begin{array}{l}10800 \times \mathrm{RM} 0.312 \\
=\mathrm{RM} 3369.60\end{array}$ \\
\hline Savings ( Actual EC - Assumed EC) & $25903-10800=15103$ & $\begin{array}{l}25543 \times \mathrm{RM} 0.312= \\
\mathrm{RM} 4712.14\end{array}$ \\
\hline
\end{tabular}

Note: that RMo.312 is the tariff provided by government for electrical bills

The data recorded for every 15 minutes and 24 data per day for the month of September 2013 was analyzed. The actual total consumption of electricity after 12.00 am until 5.45 am for September 2013 is $25903 \mathrm{kwH}$ or RM8081.74. Based on the data at this time, the usage should be lower or at an average of $15 \mathrm{kwH}$ per 15 minutes. Let's say we set the average at $15 \mathrm{kwh}$, the total consumption is $10800 \mathrm{kwH}$ or RM 3369.60. By practicing energy saving, we can save up to 15103 kwH or RM 4712.14 per month. The cost to implement the system (automatic shutdown) is much lesser to decrease the electrical consumption and reduce electricity costs in FSKM.

Secondly, based on the monthly usage of October 2013, the total electrical consumption is 137, $132 \mathrm{kwH}$ or RM 42, 785.18. If we want to reduce the electrical usage by RM 10,000 or 32, $051 \mathrm{kwH}$, we need to reduce the total electrical consumption to $105,081 \mathrm{kwH}(\mathrm{RM} 32,785.18)$ by $23.37 \%$.

Table-1.3. Electrical Consumption for Reduction by RM 10, 000

\begin{tabular}{|c|c|c|}
\hline Electrical Consumption & kwH & $\mathbf{R M}$ \\
\hline $\begin{array}{l}\text { Total electrical consumption For } \\
\text { October } 2013\end{array}$ & 137,132 & $\begin{array}{l}137,132 \times \mathrm{RM} 0.312= \\
42,785.18\end{array}$ \\
\hline If we want to reduce by RM 10,000 & $\begin{array}{l}\mathrm{RM} 10,000 / \mathrm{RMO} \\
.312 \\
=32,051\end{array}$ & $\begin{array}{l}42,785.18-10,000= \\
32,785.18\end{array}$ \\
\hline $\begin{array}{l}\text { Forecast for new total electrical } \\
\text { consumption For November } 2013\end{array}$ & $\begin{array}{l}137,132-32,051 \\
\quad=105,081\end{array}$ & $\begin{array}{l}32,785.18 \text { (Reduction by } \\
23.37 \%): \\
((42,785.18-32,785.18) / 42, \\
785.18)\end{array}$ \\
\hline
\end{tabular}

Note that RM0.312 is the tariff provided by government for electrical bills

The reduction can be achieved when strict policies are introduced to ensure the staffs and students follow the rules. Firstly, air-conditioner should be at $24^{\circ} \mathrm{C}$ as the normal temperature level and to close all door and windows when air-conditioner is on. The size of air-conditioners must be suitable to maintain the temperature of the area. Otherwise, the fan in the air-conditioner will continue operating until the area maintains its temperature. This would lead to an increase in 
the usage of electricity. It is important that during lunch hour, all the electrical components especially air-conditioner are switched off. Even one hour reduction can greatly affect the electrical bills of FSKM. It is important to manage the class time table properly. If the course does not need to use computer laboratory, do not give permission for the class to be conducted in the laboratory. Next, students and staff should not be in faculty after $10.00 \mathrm{pm}$.

\section{CONCLUSION}

Through the course of this project, a number of objectives were achieved. The electricity usage at Faculty of Computer \& Mathematical Sciences (FSKM) were collected and analyzed. The Six Sigma methodology was used and involves a systematic DMAIC process which is abbreviated from Define, Measure, Analyze, Improve and Control. Pareto chart shows that air-conditioner is the major electrical component that contributes to high consumption of electricity. After the Energy Conservation (EC) campaign, there is a reduction of electricity consumptions at Faculty of Computer \& Mathematical Sciences. We hope the energy conservation initiative campaign that we piloted will serve as a foundation for similar energy conservation initiatives in the future for other faculties in University Technology MARA (UiTM)

\section{RECOMMENDATION FOR FUTURE RESEARCH}

Electrical consumption is the total amount of electrical energy used by electrical devices and is measured in kilowatt hours $(\mathrm{kwH})$. By continuously monitoring electrical consumptions, the amount of electricity usage can be reduced. This practice is known as energy conservation. Conserving energy is good for the planet and may also reduce expenditure on electrical bills. Monitoring electricity consumption is easy and will only take a few minutes of our time. The following are some recommendations to reduce electrical usage especially address on conditioner air that has been suggested as a major impact on electricity consumption.

The air pressure inside a closed air-conditioning room is normally higher compared to the outside. In case the windows are not closed properly, or if there is gap between inside and outside of the room, the air will tend to escape and cause energy to be lost. Furthermore, energy saving compressor such as the inverter type need to be widely promoted as part of energy conservation initiatives. Direct sunlight also can cause heat to be trapped inside closed room. Some ways to prevent heat entrapment is to add light shield such as shades or tinted glass windows. Curtains sometime are effective to prevent this dissipated heat as installing tinted glass window sometimes is costly.

Besides, strict policies should also be introduced to reduce the electrical consumption in FSKM. For example, the temperature of air-conditioner should be maintained at $24{ }^{\circ} \mathrm{C}$. Even our government also had introduced the policy but it is not being strictly implemented in UiTM. Additionally, policies about the utilities that cannot be used by staffs at the University such as cup heater, rice cooker or mini fridge should also be implemented. Cup heater actually used high usage of energy to maintain the temperature of the water itself. Other than such, students and staffs should not be in the campus area after midnight. 


\section{REFERENCES}

Ansari, D. Lockwood, E. Thies, B. Modarress and J. Nino, 2009. Application of six-sigma in finance: A case study. Journal of Case Research in Business and Economics, 3(1): 1-13.

Arshad, M., M.T. Rasool and M.I. Ahmad, 2003. Anderson darling and modified anderson darling tests for generalized pareto distribution. Pakistan Journal of Applied Sciences, 3(2): 85-88.

Brandon, G. and A. Lewis, 1999. Reducing household energy consumption: A qualitative and quantitative field case study. Journal of Case Research in Business and Economics, 3(1): 1-13.

Chambers, J.M., W.S. Cleveland, B. Kleiner and P.A. Tukey, 1983. Graphical methods for data analysis. Wadsworth, Belmont, California CO. International Journal of Sustainability in Higher Education, $8(1): 16-33$.

Farrell, P.J. and K. Rogers-Stewart, 2006. Comprehensive study of tests for normality and symmetry. Extending the spiegelhalter test. J. Statist. Comput. Simul, 76(9): 803-816.

Fursule, N.V., S.V. Bansod and S.N. Fursule, 2012. Understanding the benefits and limitations of six sigma methodology. International Journal of Scientific and Research Publications, 2(1): 1-9.

Heede, R. and J. Swisher, 2002. Oberlin: Climate neutral by 2020, report, rocky mountain institute, snowmass, individuals' feeling in community with nature. Journal of Environmental Psychology, $24(4): 503-515$.

Mayer, S.F. and C.M. Frantz, 2004. The connectedness to nature scale: A measure of methodology. Journal of Scientific and Research Publication, 2(1): 2250-3153.

Petersen, J.E., V. Shunturov, K. Janda, G. Platt and K. Weinberger, 2007. Dormitory residents reduce philadelphia: Society for industrial and applied mathematics study. International Journal of Sustainability in Higher Education, 8(1): 16-33.

\section{BIBLOGRAPHY}

Niederreiter, H., 1992. Random number generation and Quasi-Monte Carlo Methods. Of SIAM CBMS-NSF Regional Conference Series in Applied Mathematics. Philadelphia: SIAM, 63. 